Simon PETROVČIČ

David KOREN

Vojko KILAR

\title{
Možnosti uporabe potresne izolacije iz elastomernih ležišč za varstvo kulturne dediščine
}

V članku so na kratko prikazane možnosti za uporabo potresne izolacije iz elastomernih ležišč pri varstvu objektov arhitekturne dediščine. V prvem delu članka so za ponazoritev prikazani nekateri primeri uporabe izolacije $\mathbf{v}$ svetu ter analiza smernic za ohranjanje in upravljanje kulturne dediščine, ki jih podajajo nekatere listine in mednarodne resolucije o varovanju spomenikov ter jih je treba upoštevati pri projektiranju potresne izolacije kulturnega spomenika. V splošnem morajo posegi v objekte kulturne dediščine, s katerimi lahko povečamo potresno varnost, $\mathrm{v}$ čim manjši meri vplivati na lep videz in funkcionalnost objekta. $\mathrm{V}$ drugem delu članka so podane splošne zahteve za projektiranje elastomernih ležišč in nekoliko podrobnejša analiza posebnih zahtev, ki vplivajo na projektiranje izolacijskega sistema. Podrobneje je prikazana analiza vpliva vitkosti objekta na izbiro izolacije, ki preprečuje nastop nateznih napetosti v ležiščih oziroma prevrnitev izolirane- ga objekta. Konec članka prinaša prikaz izračunanih maksimalnih razmerij višine proti širini objekta, ki ga je ob upoštevanju nevarnosti prevrnitve še mogoče postaviti na izolatorje na tleh, ki so različne kvalitete. Maksimalna razmerja med višino in širino objekta so izračunana tudi za 5 skaliranih potresnih zapisov za potres leta 1998 v Posočju.

Ključne besede: kulturna dediščina, arhitekturni spomeniki, potresna izolacija, elastomerna ležišča, potresna varnost, ukrepi za povečanje potresne varnosti 


\section{Uvod}

Povečanje potresne varnosti že zgrajenih objektov zahteva razmeroma velike in drage posege $\mathrm{v}$ objekt, zato se popravila že zgrajenih stanovanjskih in poslovnih objektov izvajajo le, kadar je to res nujno potrebno. Povsem drugačne pa so razmere pri stavbah s posebno vsebino, ki imajo na primer visoko finančno ali kulturno vrednost. V slednjo skupino spadajo predvsem objekti kulturne dediščine, za katere smo pripravljeni uporabiti tudi dražje tehnološke rešitve za njihovo zaščito med potresom. V kontekstu tega članka pod pojmom kulturna dediščina razumemo objekte arhitekturne dedišcine, torej kulturne spomenike, ki imajo poleg praktične in funkcionalne vrednosti tudi posebne kulturne in zgodovinske lastnosti (Fister, 1979).

Večjo potresno varnost lahko dosežemo z vstavljanjem posebnih mehkih elementov (ležišč), ki jih najpogosteje vgrajujemo med konstrukcijo in njene temelje, da zmanjšamo energijo, ki jo potres dovaja v konstrukcijo. Glavna naloga izolacijskih naprav je, da povečajo nihajno dobo konstrukcije in tako zmanjšajo raven sil, ki nastopijo med potresom. Izkušnje zadnjih potresov kažejo, da se izolirani objekti dejansko obnašajo v skladu s pričakovanji, torej da zmanjšujejo poškodbe, ki nastanejo med potresom (Naeim in Kelly, 1999).

Obnova objektov arhitekturne dediščine je zaradi njihove visoke kulturne vrednosti navadno zelo zahtevna. Kot navaja burrska listina (ICOMOS, 1999), moramo prostore kulturne dediščine varovati in jih ne smemo puščati nezašcitenih. Posegi v takšne objekte morajo biti minimalni oziroma čim manj vidni in morajo v čim manjši meri vplivati na lep videz in funkcionalnost objekta. Zaželeno je, da se pri rekonstrukcijah uporablja čim več materialov, ki so enaki že vgrajenim materialom. Takšni materiali pogosto ne izpolnjujejo zahtev o mehanski odpornosti kot sodobnejši materiali in $s$ tem ne prispevajo bistveno $\mathrm{k}$ povečanju potresne varnosti. Velikokrat že zasnova starejših objektov ni ugodna s stališča potresne varnosti. Potresna izolacija je v tem pogledu svojevrstno rešitev, saj omogoča večjo potresno varnost objektov arhitekturne dediščine $\mathrm{z}$ minimalnim poseganjem $\mathrm{v}$ objekt.

V članku so na kratko prikazane možnosti za uporabo potresne izolacije iz elastomernih ležišč. V prvem delu članka so prikazani nekateri primeri uporabe izolacije v svetu in pregled smernic za varovanje arhitekturne dediščine, ki jih moramo upoštevati pri projektiranju potresne izolacije kulturnega spomenika. V drugem delu članka so podane splošne zahteve za projektiranje ležišč in nekoliko podrobnejša analiza posebnih zahtev, ki vplivajo na projektiranje izolacijskega sistema. Podrobneje je prikazana analiza vpliva vitkosti objekta (razmerja med njegovo višino in širino) na izbiro izolacije, ki onemogoča nastop nateznih napetosti v ležiščih oziroma prevrnitev izoliranega objekta.

\section{Uporaba izolacijskih sistemov}

Ležišča podaljšajo nihajno dobo konstrukcije in tako znižajo potresne sile, ki nastanejo na konstrukciji. Pogosto se uporabljajo t. i. mešani oziroma hibridni sistemi, ki v kombinaciji $z$ dušilci povečajo dušenje konstrukcije in s tem še dodatno znižajo raven potresnih sil na konstrukciji (Naeim in Kelly, 1999). Uporaba takega sistema za izolacijo kulturnega spomenika je prikazana na sliki 1. Zavedati se moramo, da je vgradnja oziroma projektiranje potresne izolacije vsekakor zelo posebna in za vsak projekt unikatna naloga, ki zahteva izkušene projektante in izvajalce, ter da lahko napačno projektirana in vgrajena potresna izolacija v nekaterih primerih tudi poslabša obnašanje objekta pri potresni obremenitvi (Skinner idr., 1993; Naeim in Kelly, 1999; Kilar in Koren, 2007).

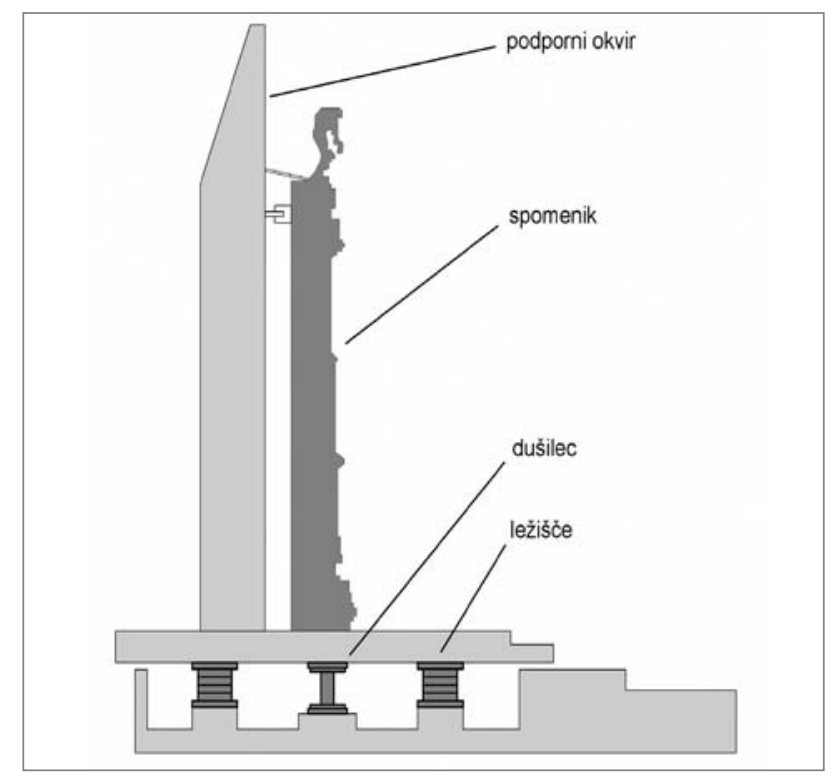

Slika 1: Rodinova Vrata v pekel, izolirana z ležišči in dušilci (vir: internet 1).

Pri obstoječih objektih je potresna izolacija zelo učinkovit način zagotovitve večje potresne varnosti, saj je poseg $\mathrm{v}$ objekt minimalen. To je še posebej pomembno pri objektih arhitekturne dediščine, ki imajo veliko kulturno vrednost. V nadaljevanju bo predstavljenih nekaj primerov rekonstrukcije objektov arhitekturne dediščine s potresno izolacijo. V Italiji so bile tako že izvedene številne obnove za povečanje potresne varnosti objektov arhitekturne dedišcine (Martelli in Forni, 1998, 2004; Indirli idr., 2006). Poleg povečanja potresne odpornosti lahko pri obnovi s potresno izolacijo povečamo tudi stabilnost konstrukcije. Tak primer je Katedrala sv. Felicijana v Folignu, ki je utrpela večje poškodbe med potresoma v Marcheju in Umbriji ter je bila kasneje ustrezno obnovljena s potresno izolacijo (Martelli in Forni, 2004). 
Potresna izolacija se vse bolj uporablja tudi pri varovanju drugih vrst kulturnih spomenikov, kot so kipi, slavoloki, obeliski in drugi podobni objekti z visoko kulturno vrednostjo. Kot zanimive primere navajamo potresno izolacijo Praxitelesovega kipa Hermesa (slika 2 in slika 3 ) v novem muzeju v grški Olimpiji, ki je bil izoliran z uporabo elastomernih ležišč (Koumousis, 2007). Kot poročajo Indirli idr. (2006) ter Koumousis (2007) so bila na podoben način izolirana tudi Rodinova Vrata v pekel v narodnem muzeju zahodnjaške umetnosti v Tokiu (slika 1), kip Afrodite v Guggenheimovem muzeju v New Yorku, Neptunov vodnjak v kraju Messina v Italiji in več razstavnih predmetov v muzeju J. Paula Gettyja v Los Angelesu. Tudi v Sloveniji, ki je na potresno ogroženem območju, obstaja več kulturno zaščitenih spomenikov, kot so na primer kipi in kapelice ter drugi objekti, ki bi jim lahko tako po potrebi povečali potresno varnost.

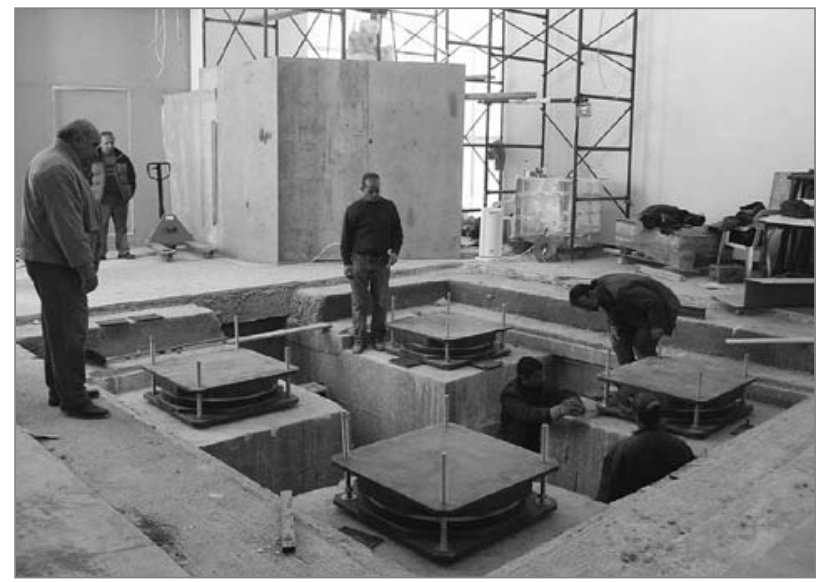

Slika 2: Namestitev potresne izolacije kipa Hermesa v Olimpiji (vir: Koumousis, 2007)

\section{Smernice za varovanje arhitekturne dediščine}

Avstralski nacionalni komite ICOMOS je leta 1979 v Burri v Južni Avstraliji sprejel t. i. burrsko listino (ICOMOS, 1999). Burrska listina določa smernice za ohranjanje in upravljanje arhitekturne dediščine. Listina temelji na znanju in izkušnjah članov avstralskega ICOMOS-a, ter tudi na mednarodni listini o konserviranju in restavriranju kulturnih spomenikov in območij (sprejeta je bila v Benetkah leta 1964) ter resoluciji s petega generalnega zasedanja mednarodnega zborovanja o spomenikih in zašcitenih območjih ICOMOS-a (sprejeta je bila v Moskvi leta 1987). Trenutno veljavna je dopolnjena izdaja listine iz novembra 1999. Kot navajajo Zupančič idr. (2007), je ena izmed glavnih prednosti te listine njena velika uporabnost, saj so v njej natančno definirali pojme, načela in postopke ohranjanja kulturne dediščine.

Bistvo ohranjanja je v burrski listini definirano kot ohranjanje kulturnega pomena prostora arhitekturne dediščine. $\mathrm{V}$

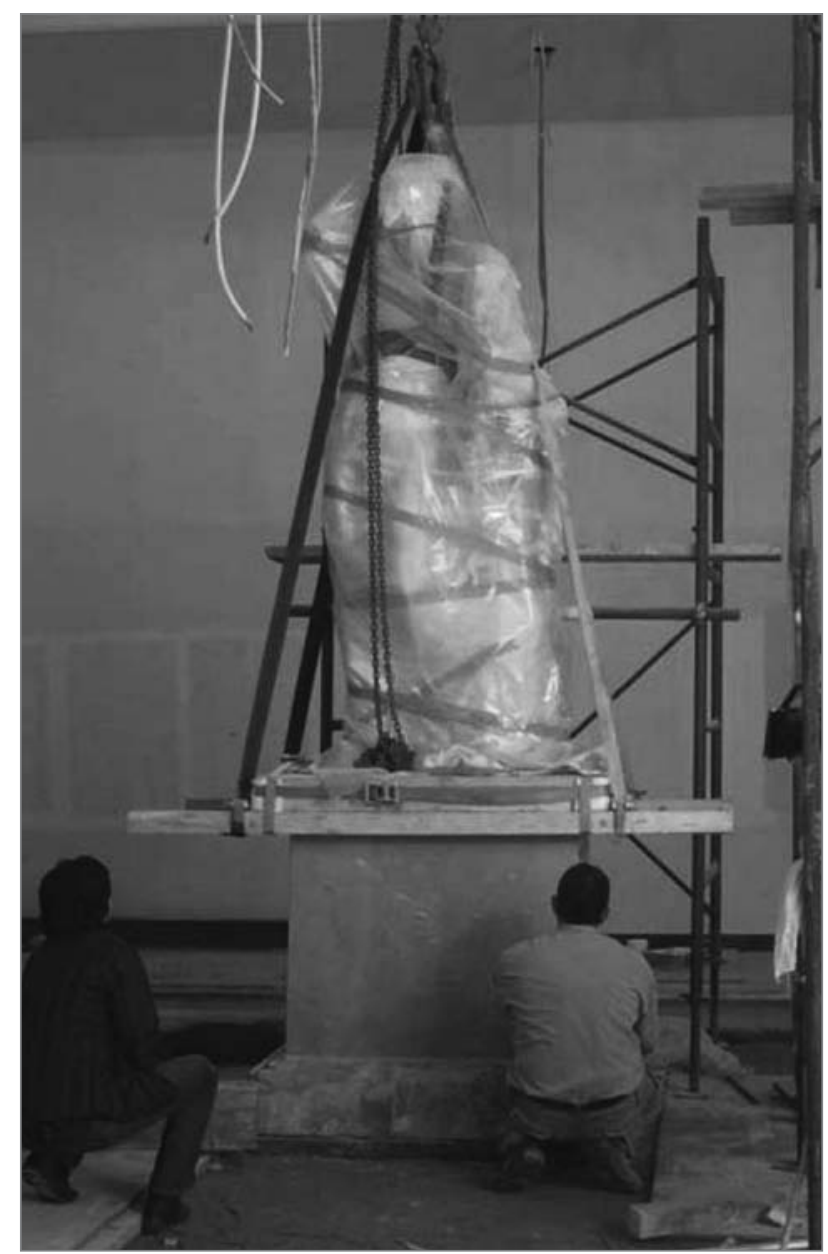

Slika 3: Namestitev kipa na potresno izolacijo (vir: Koumousis, 2007)

kontekstu tega članka tvorijo prostor arhitekturne dediščine poslopja, spomeniki, kapelice in drugi podobni objekti, ta pa obsega tudi njihove sestavne dele, vsebine in prostore. Listina navaja, da so spremembe tega prostora dopuščene le v najmanjši mogoči meri ter da ima uporaba tradicionalnih tehnik in materialov prednost pri ohranjanju prostora kulturne dediščine.

V splošnem morajo torej posegi v objekte arhitekturne dediščine, s katerimi povečamo potresno varnost, $v$ čim manjši meri vplivati na lep videz in funkcionalnost objekta. Obstaja težnja, po kateri se pri takšnih posegih poskuša najti kompromis med doseganjem zadostne stopnje potresne varnosti in čim manjšim poseganjem v prvotni objekt (Amerighi idr., 2007). Načini za doseganje takšnega harmoniziranega delovanja, ki zajemajo tehnike gradnje, določitev potresne ogroženosti, porušne mehanizme in metode obnove, temelijijo predvsem na izkušnjah iz preteklih obnov. Organizacija UNESCO je v sodelovanju z ICOMOS-om določila smernice, ki določajo, kaj vse mora posamezni strokovnjak obvladati, da se lahko ukvarja s prenovo arhitekturne dediščine. Zupančič (2007) podaja v članku pregled vseh 14 smernic. Poseben poudarek daje projektu statične obnove arhitekturne dediščine, med katero spada tudi obnova $s$ potresno izolacijo. 
Za načrtovanje prenove s potresno izolacijo sta od prej omenjenih smernic posebej pomembni točki $f$ in $j$. $V$ točki $f$ je predvidena interdisciplinarna analiza tehnoloških, okoljskih in drugih vzrokov za poškodbe, pri katerih je izhodišče za ustrezno ukrepanje diagnoza notranjih in zunanjih vplivov propada. $\mathrm{V}$ točki $\mathrm{j}$ se priporoča izvajanje dodatnih raziskav, ki lahko dopolnijo obstoječe načrte za prenovo. Pod pojmom dodatne raziskave so mišljene predvsem dodatne specialistične raziskave tehnologije gradiv in statičnih sistemov. Na podlagi teh dveh smernic določimo stopnjo potresne ogroženosti obravnavanega objekta in v sklopu projekta statične obnove arhitekturne dediščine izdelamo načrt prenove s potresno izolacijo.

Indirli idr. (2006) v članku navajajo predloge, kako in v kolikšni meri se med prenovami sme posegati v objekte arhitekturne dediščine. Predloge lahko povzamemo v teh točkah:

1. Odstopanja od predpisov in kriterijev, ki veljajo za nove stavbe, so dovoljena, ker takšni objekti navadno niso zgrajeni iz sodobnih materialov, kot sta armirani beton in jeklo, ter je njihova obnova zahtevna.

2. V predpisih, ki obravnavajo objekte po teoriji $\gg$ mejnih stanj « (na primer standardi Evrokod), se lahko faktor pomembnosti posebej določi za posamezni objekt.

3. Učinkovitost izboljšav naj se vrednoti sproti.

4. Priporočljive so natančne predhodne študije.

5. Priporoča se uporaba posebnih postopkov, ki so izdelani za vsak obnovitveni projekt posebej, saj uporaba standardnih postopkov pri obnovi pogosto ni mogoča.

6. Priporočeno je upoštevanje nenapisanih, izkustvenih pravil gradnje objektov.

7. Uporaba sodobnih materialov lahko močno poveča stopnjo potresne varnosti objekta, vendar uporaba takšnih materialov ne sme biti estetsko moteča in mora biti združljiva z že vgrajenimi materiali.

\section{Splošne zahteve za projektiranje ležišč}

Projektiranje ležišč potresne izolacije stavbe je razmeroma zahtevno, saj gre za dinamični sistem, v katerem imata pomembno vlogo togost zgornje in spodnje konstrukcije. Neustrezno projektiran sistem lahko povzroči več škode kot koristi, če nihajni čas konstrukcije prestavi v čas prevladujočih dob potresa in zato pride do resonančnega odziva.

Splošne zahteve, ki jih je treba izpolniti pri projektiranju ležišč, so podane v predpisu Evrokod 8 (CEN, 2004), podrobno opisane in razložene pa so tudi v znanstveni literaturi Skinner idr. (1993), Kelly (1997), Naeim in Kelly (1999), Komodromos (2000) ter Christopoulos in Filiatrault (2006). V nadaljevanju so predstavljene zahteve, ki so pomembne za projektiranje potresne izolacije objektov arhitekturne dediščine.

Za izpolnitev osnovnih zahtev je treba preveriti mejno stanje nosilnosti, ki je povezano s porušitvijo ali z drugimi oblikami odpovedi konstrukcije, ki lahko ogrozijo varnost ljudi in mejno stanje uporabnosti, ki je povezano s poškodbami na meji uporabnosti. Pri poškodbah, večjih od teh, pogoji, predpisani za obratovanje, niso več izpolnjeni. V obeh mejnih stanjih ne sme biti presežena mejna nosilnost in deformabilnost izolacijskih naprav. Predpis zahteva tudi povečano zanesljivost izolacijskih naprav, ki se doseže tako, da se pomik vsake naprave zaradi potresa poveča za $20 \%$.

Poleg tega mora vsako ležišče biti sposobno prenašati navpične obtežbe, imeti mora sposobnost sipanja energije in povrnitve $\mathrm{v}$ začetno lego ter zadostno elastično togost za prevzem vodoravnih obtežb, ki niso potresnega izvora (na primer veter). Pomembno je, da je izolirana konstrukcija dovolj ločena od okoliške zemljine in ostalih konstrukcij, tako da se lahko v potresnem projektnem stanju prosto giblje v vseh horizontalnih smereh. Da bi bili torzijski vplivi čim manjši, je priporočljivo, da sta centra togosti in dušenja izolacijskega sistema čim bliže točki projekcije centra mas na izolacijsko ploskev. Tlačne napetosti, ki jih stalni vplivi povzročajo v napravah, morajo biti čim enakomernejše, saj se tako zmanjšajo razlike v obnašanju izolacijskih naprav. Ležišča morajo biti pritrjena v zgornjo in spodnjo konstrukcijo tako, da se nad izolacijskim sistemom in pod njim izvede toga konstrukcija (diafragma), na primer toga plošča ali brana iz veznih gred, ki je projektirana tako, da je preprečen njen lokalni in globalni uklon.

Pri preverjanju spodnje konstrukcije je treba upoštevati vztrajnostne sile, ki delujejo neposredno nanjo ter sile in momente, ki se vanjo prenašajo prek izolacijskega sistema. Mejno stanje izolacijskih naprav se, glede na tip uporabljenih naprav, preveri s silami, pri čemer se upošteva tudi učinke prevračanja. Pri silah se upošteva največje mogoče navpične in vodoravne sile v potresnem projektnem stanju. Lahko pa mejno stanje izolacijskih naprav preverimo tudi s skupnim relativnim vodoravnim pomikom med spodnjo in zgornjo stranjo naprave, pri katerem upoštevamo deformacijo zaradi projektnega potresnega vpliva ter tudi druge vplive kot so na primer krčenje, tečenje in spremembe temperature.

$\mathrm{Na}$ izbor ustreznega sistema potresne izolacije vpliva torej več med seboj izključujočih se faktorjev. Tako na primer z določenim izolacijskim sistemom po eni strani zmanjšamo celotno horizontalno potresno silo, po drugi strani pa povečamo pomike izolacijskega sistema. Učinkovit izolacijski sistem ustrezno zmanjša potresno silo, ki se lahko med potresom prenese na zgornjo konstrukcijo, pri čemer pa mejni pomik izolacijskega 
sistema (določa ga zmogljiivost ležišč in druge zahteve za širino dilatacij) ne sme biti presežen. Izbira končnega izolacijskega sistema je torej odvisna od celotne horizontalne sile, ki nastane pri potresni obremenitvi, in od želenega vodoravnega pomika izoliranega sistema ter tudi od pomembnosti vsebine objekta in seveda razpoložljivih finančnih sredstev.

Učinkovitost izolacijskega sistema je v veliki meri odvisna tudi od »vitkosti « objekta, to je razmerja med njegovo višino in širino (Li in Wu, 2006; Egidio in Contento, 2008; Hino idr., 2008). Pri objektih z velikim razmerjem med višino in širino je namreč nevaren pojav zibanja objekta (ang. rocking), ki ga povzročijo potresne sile in lahko vodi do dviga ležišč oziroma prevrnitve potresno izoliranega objekta. Hino idr. (2008) podajajo kriterija, ki določata mejno maksimalno vitkost izoliranega objekta:

- omejitev nateznih napetosti in preprečitev dviga,

- omejiter maksimalne tlačne sile v ležišču pri zibanju.

Pri tem je treba upoštevati delovanje potresnih sil v horizontalni in vertikalni smeri. Obnašanje elastomernih ležišč je namreč v nategu veliko slabše kot obnašanje v tlaku (Skinner idr., 1993; Kelly, 1997). Natezne napetosti povzročijo v ležiščih majhne razpoke, ki počasi rastejo pod cikličnim obremenjevanjem in bistveno zmanjšujejo vertikalno togost ležišč (Skinner idr., 1993). Številni avtorji, kot na primer Skinner idr. (1993), Kelly (1997), Li in Wu (2006) zato priporočajo, naj se natezne trdnosti ležišč ne upošteva pri projektiranju oziroma da morajo biti ležišča projektirana tako, kot da niso sposobna prenašati nateznih obremenitev. Omenjene posebne zahteve, ki se nanašajo na nastop nateznih napetosti in na $s$ tem povezano maksimalno dovoljeno vitkost objekta, bodo nekoliko podrobneje prikazane v nadaljevanju.

\section{Posebne zahteve za projektiranje elastomernih ležišč}

\subsection{Izključitev nateznih napetosti in preprečitev dviga}

Eden od kriterijev kontrole mejnega stanja ležišč je tudi izključitev nateznih napetosti v ležiščih (oziroma dviga ležišč), ki bi lahko povzročile prekinitev povezave med ležišči in objektom ter poškodbe v ležiščih, kar lahko v skrajnem primeru pripelje tudi do porušitve objekta ( $\mathrm{Li}$ in Wu, 2006). Kot bo prikazano v nadaljevanju, je pomemben parameter, ki pogojuje pojav nateznih napetosti v ležiščih, razmerje med višino in širino obravnavanega objekta, t. i. »vitkost « objekta.

Slika 4 prikazuje potresno izoliran sistem, ki ga sestavljata objekt višine $H$ in širine $B$, temeljna brana in potresna izolacija iz elastomernih ležišč. Pri razporeditvi ležišč lahko predvidevamo, da so ležišča tlorisno razporejena $\mathrm{v} n$ vrstah po ortogonalni mreži. Razdalja med posameznimi vrstami ležišč je konstantna.

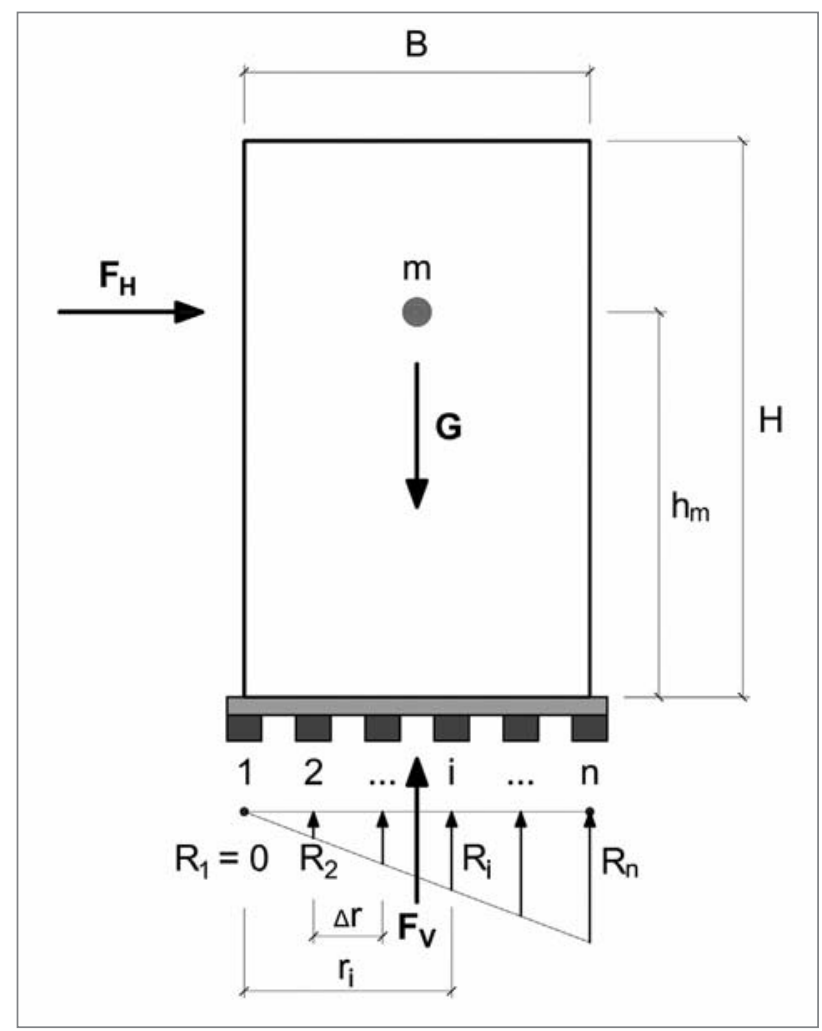

Slika 4: Potresno izoliran sistem togega telesa z n vrstami ležišč tik preden pride do zibanja objekta.

Domnevamo lahko tudi, da je zgornja konstrukcija togo telo, ki se translacijsko premika na izolacijskem sistemu v horizontalni in (ali) v vertikalni smeri. Menimo, da je ta domneva smiselna za stavbe arhitekturne dediščine, ki so običajno precej toge, vendar pa $v$ elastičnem območju ne morejo prenesti večjih obremenitev in nateznih napetosti. Masno središče celotnega sistema, ki zajema maso objekta in maso temeljne brane, je na višini $h_{m}$.

Na obravnavani sistem delujeta horizontalna potresna sila $F H$, vertikalna potresna sila $F V$ in sila teže G. Kot pogoj za določitev maksimalne vitkosti (razmerja $H / B$ ) je upoštevana zahteva, da se v ležiščih ne pojavijo natezne napetosti. Mejno stanje tik pred nastopom zibanja je doseženo, ko je reakcija $R_{l}$ enaka nič, vse ostale reakcije v ležiščih pa so tlačne, kot prikazuje slika 4 . Pogoj za nastop zibanja lahko zapišemo kot momentni pogoj na prvo vrsto ležiščc. Ker je razmak med ležišči konstanten, lahko vertikalne reakcije in njihove ročice izrazimo kot delež največje tlačne reakcije $R_{n}$, v odvisnosti od širine $B$ in števila izolatorjev $n$. Celotna izpeljava pogoja je za poljubno število $n$ razmeroma zapletena in na tem mestu ne bo podana, prikazujemo le končni izpeljani izraz za maksimalno korigirano razmerje $H / B$, ki ga imenujemo korigirana vitkost in ga označimo $\mathrm{z} \lambda$ : 
$\lambda \equiv k_{m} \cdot k_{n} \frac{H}{B}=\frac{1}{2} \cdot \frac{G-F_{F}}{F_{H}} \quad ; \quad k_{m}=\frac{h_{m}}{H} \quad ; \quad k_{n}=3-\frac{6}{n+1}$

Vidimo lahko, da je korigirana vitkost $\lambda$ odvisna od razmerja med vertikalno silo $F_{V}$ in horizontalno silo $F_{H}$, silo teže $G$. Koeficienta $k_{m}$ in $k_{n}$ vključujeta vpliv lege masnega središča in vpliv števila vrst ležišč. Koeficient $k_{m}$ lahko zavzame vrednosti med 0 in 1 , koeficient $k_{n}$ pa vrednosti med 1 in 3 , pri čemer ima koeficient $k_{n}$, če imamo samo 2 vrsti ležǐ̌č $(n=2)$, vrednost 1 , pri velikem številu ležišč pa se njegova vrednost približuje 3 (jedro prereza). Potek koeficienta $k_{n} \mathrm{v}$ odvisnosti od $n$ prikazuje slika 5 .

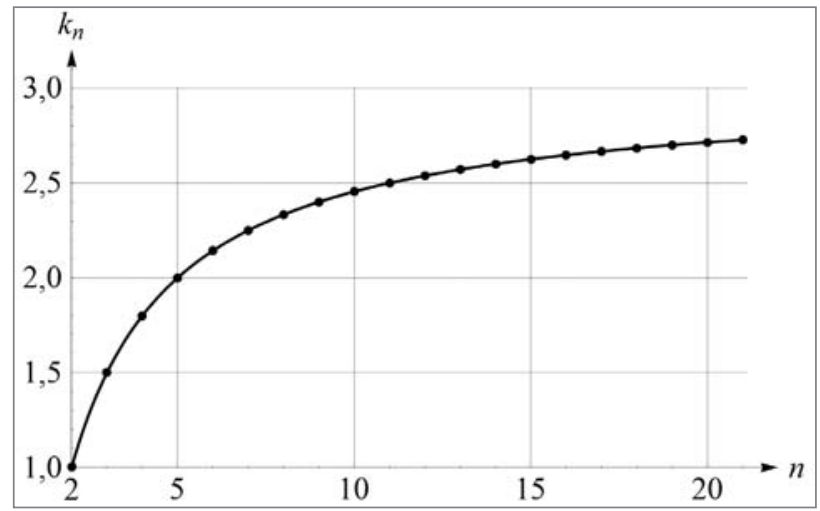

Slika 5: Vrednosti koeficienta $k_{n} \vee$ odvisnosti od števila vrst ležišč $n$

Korigirana vitkost $\lambda$ pomeni korigirano maksimalno razmerje $H / B$, ki ga ima lahko neki izoliran sistem, ne da bi zaradi delovanja horizontalne in vertikalne sile prišlo do zibanja objekta oziroma do pojava nateznih napetosti v elastomernih ležiščih. Razmerje je korigirano s koeficientoma $k_{m}$ in $k_{n}$. Če oba koeficienta zavzameta vrednost $1\left(b_{m}=H\right.$ in $\left.n=2\right)$, pomeni korigirana vitkost $\lambda$ dejansko maksimalno razmerje $H / B$.

\subsection{Omejitev maksimalne tlačne sile v ležišču}

Dokler na objekt deluje le vertikalna obtežba, je tlačna sila v vseh ležiščih enaka in je odvisna le od števila in razporeditve ležišč. Pri hkratnem delovanju horizontalne in vertikalne obtežbe so reakcije na eni strani objekta večje kot na drugi. Tik pred nastopom zibanja (slika 4) je reakcija enaka nič, hkrati pa je tlačna sila na drugi strani precej večja, kot če deluje samo vertikalna obtežba. Izrazimo jo lahko v odvisnosti od normirane dovoljene vitkosti $\lambda$, števila ležišč $n$ in horizontalne potresne sile:

$$
R_{n}=\frac{4 \cdot F_{H} \cdot \lambda}{n}
$$

Pri neki izbrani korigirani vitkosti $\lambda$ pomeni reakcija $R_{n}$ maksimalno tlačno silo, ki se lahko pojavi v robnih ležiščih, kar določa dodaten pogoj, ki ga moramo upoštevati pri projektiranju ležišč.

\section{Določitev mejne vitkosti}

\subsection{Določitev mejne vitkosti s pomočjo spektra odziva}

Pri analizi s spektrom odziva določimo sili $F_{V}$ in $F_{H}$ iz enačbe 1 kot produkt mase in vertikalnega oziroma horizontalnega pospeška, ki ga dobimo iz elastičnega spektra odziva po Evrokodu 8 (CEN, 2004) pri določenem vertikalnem in horizontalnem nihajnem času $T_{V}$ in $T$. Horizontalni in vertikalni nihajni čas ležišč v splošnem nista enaka. Komodromos (2000) navaja, da se vertikalne frekvence elastomernih ležišč gibljejo med 8 in $12 \mathrm{~Hz}$, kar ustreza nihajnemu času približno $0,1 \mathrm{~s}$. V nadaljevanju smo zato domnevali, da je vertikalni nihajni čas vedno v platoju spektra za vertikalne pospeške. Pri računu s spektrom

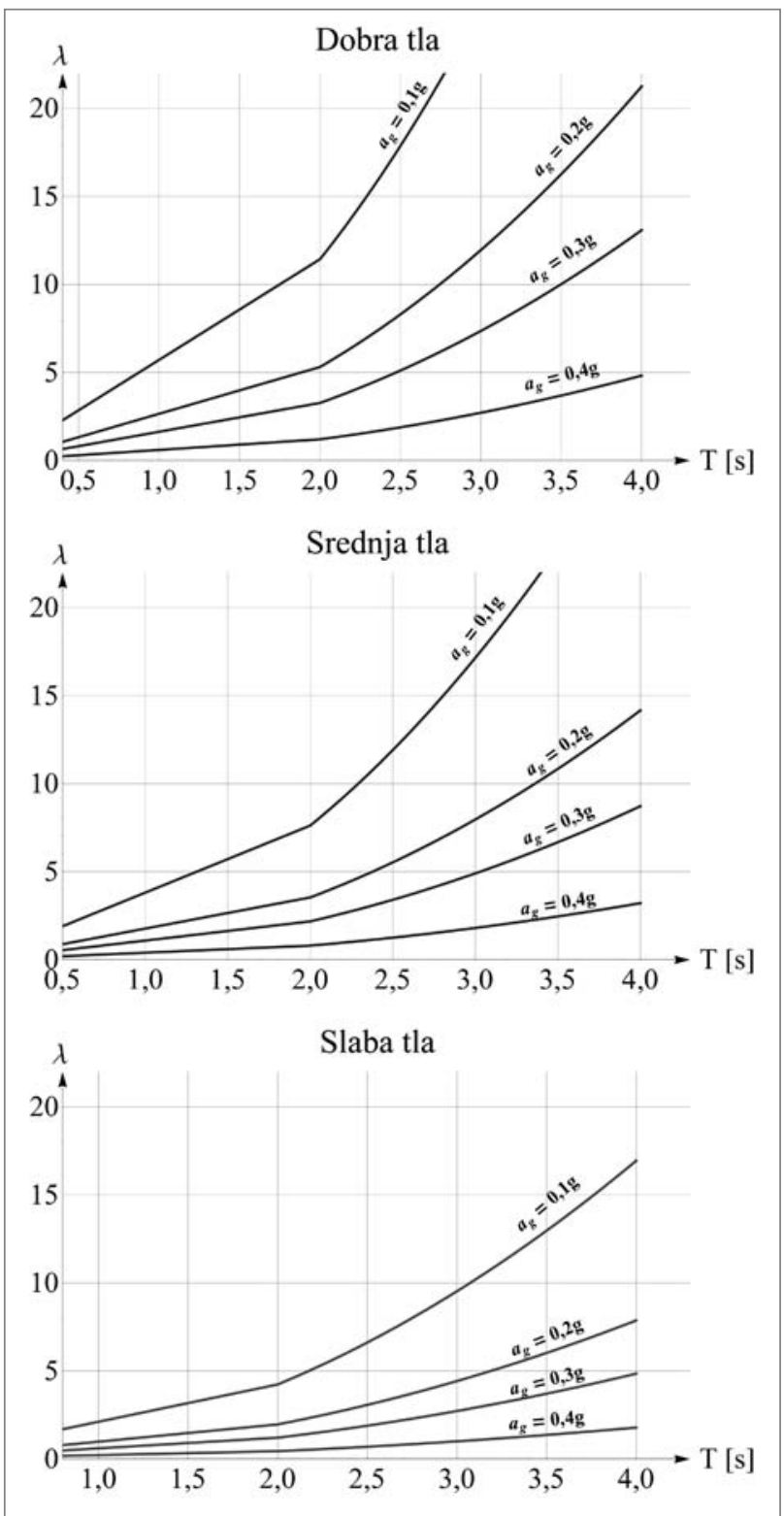

Slika 6: Korigirana vitkost v odvisnosti od nihajnega časa za tri tipe tal 
Evrokod 8 zahteva tudi, da je pri potresnem vzbujanju v dveh smereh treba upoštevati 100-stoodstotno vrednost maksimalnega vpliva $\mathrm{v}$ eni smeri in 30-odstotno vrednost maksimalnega vpliva v drugi smeri. Pri tem so vse vrednosti odvisne še od projektnega pospeška tal $a_{g}(g)$, vrste tal in dušenja elastomernih ležišč. Ob upoštevanju najmanj ugodne kombinacije, ki daje največjo še dovoljeno vitkost za neki izbran $T$, je izračunana merodajna korigirana vitkost $\lambda$ prikazana na sliki 6 za tri tipe tal - dobra tla, srednja tla in slaba tla. Začetni nihajni časi so izbrani tako, da se za vsak tip tal nahajajo zunaj platoja spektra, torej $0,4 \mathrm{~s}$ za dobra tla, $0,5 \mathrm{~s}$ za srednja tla in $0,8 \mathrm{~s}$ za slaba tla. Tipi tal ustrezajo tipom tal A, B in D, ki jih podaja Evrokod 8. Upoštevano dušenje znaša 10-odstotkov kritičnega dušenja.

Vidimo lahko, da kakovost tal bistveno vpliva na korigirano vitkost. Pri istem nihajnem času imamo lahko na dobrih tleh kar $50 \%$ večjo maksimalno dovoljeno korigirano vitkost kot na slabih tleh.

\subsection{Določitev mejne vitkosti s pomočjo dinamične analize}

Pri dinamični analizi potresne obtežbe, pri kateri so pospeški tal funkcije časa $t$, sta sili $F_{H}$ in $F_{V}$, ki delujeta na objekt, prav tako funkciji časa $t$. Sili sta odvisni od horizontalnega in vertikalnega pospeška $a_{H}(t)$ in $a_{V}(t)$, ki delujeta v masnem središču sistema. Pospeška sta odvisna od načina vzbujanja (akcelerogram), togosti (nihajnega časa) sistema izolacije, mase in dušenja $\mathrm{v}$ horizontalni oziroma v vertikalni smeri ter ju lahko izračunamo po metodah dinamike konstrukcij (Fajfar, 1984). Vertikalni in horizontalni časovni potek pospeškov imata vsak svojo maksimalno vrednost, ki pa ne nastopita nujno v istem času. V splošnem kritična kombinacija za določitev največje dovoljene korigirane vitkosti $\lambda$ ne nastane, ko eden izmed pospeškov pri izbranih nihajnih časih doseže svoj maksimum. Za pogoj pojava nateznih napetosti v ležǐščih je pomemben trenutek, $\mathrm{v}$ katerem sta oba pospeška največja $\mathrm{v}$ istem času $t$, oziroma čas, $v$ katerem tvorita najneugodnejše razmerje med vertikalno silo $F_{V}$ in horizontalno silo $F_{H}$, ki da najmanjšo kori- girano vitkost $\lambda$. Pri tem sta oba kritična pospeška odvisna še od togosti (nihajnega časa) in dušenja sistema ležišč v horizontalni oziroma v vertikalni smeri. Kritična kombinacija za določitev korigirane vitkosti $\lambda$ se torej ves čas spreminja v odvisnosti od nihajnih časov in dušenja. Enačbo gibanja je zato treba rešiti za vse nihajne čase $T \mathrm{v}$ nekem izbranem razponu, posebej za vsak potres (akcelerogram) in za vsako izbrano dušenje, vsakič posebej za horizontalno in za vertikalno smer.

Kot primer smo maksimalno dovoljeno korigirano vitkost določili za 5 izbranih akcelerogramov potresa v Posočju leta 1998, ki so bili posneti na različnih lokacijah za srednji tip tal (preglednica 1). Pri vsakem akcelerogramu je upoštevana horizontalna in vertikalna komponenta.

Zapisi z ožjega potresnega območja med glavnim potresom v Posočju leta 1998 ne obstajajo, glede na ocenjeno intenziteto in efektivne vrednosti projektnega pospeška tal pa naj bi ta znašal med $0,1 \mathrm{~g}$ in $0,2 \mathrm{~g}$ (Tomaževič idr., 1999). V sklopu analize smo se zato omejili na projektni pospešek tal $a_{g}=0,2 \mathrm{~g}$ in vse horizontalne akcelerograme skalirali na $a_{g, h}=0,2 \mathrm{~g}$. Z istim faktorjem je bil skaliran tudi vertikalni pospešek tal $a_{g, v}$, tako da se razmerje med vertikalnim in horizontalnim pospeškom tal $a_{g, v} / a_{g, b}$ ohranja. Rezultati dinamične analize so prikazani na sliki 7. Prikazana je odvisnost korigirane vitkosti $\lambda$ od nihajnega časa za vse izbrane akcelerograme in njena povprečna vrednost. Poleg rezultatov dinamičnih analiz je na sliki 7 prikazana tudi krivulja, dobljena po spektru iz Evrokoda 8 (glej poglavje 6.1).

S slike 7 lahko vidimo, da je povprečje dinamičnih analiz za korigirano vitkost $\lambda$ višje kot krivulja za $\lambda$, dobljena po spektru pospeškov iz predpisa Evrokod 8, zato je torej za izbrano povprečje akcelerogramov na varni strani. Vidimo lahko tudi, da so krivulje za akcelerograme I., IV. in V. pri določenih nihajnih časih pod Evrokodovo krivuljo in da bi bil v teh primerih račun s spektrom na nevarni strani. Najbolj kritična je krivulja, ki jo daje akcelerogram $\mathrm{V}$., in sicer za vse nihajne čase, večje od $0,6 \mathrm{~s}$. Maksimalna korigirana vitkost je $\mathrm{v}$ tem primeru približno konstantna, njena najmanjša vrednost pa znaša $\lambda=1,0$. To pomeni precejšnje zmanjšanje dovoljene vitkosti. Če je na

Preglednica 1: Izbrani akcelerogrami za potres v Posočju leta 1998

\begin{tabular}{|c|c|c|c|c|c|c|}
\hline Oznaka & Ime merilne postaje & $\begin{array}{c}\text { Številka zapisa } \\
\text { v bazi ESD }\end{array}$ & $\begin{array}{l}\text { Oddaljenost od preloma } \\
\qquad(\mathrm{km})\end{array}$ & $\begin{array}{l}a_{g, H} \\
(g)\end{array}$ & $\begin{array}{l}a_{g, v} \\
(g)\end{array}$ & $a_{g, V} / a_{g, H}$ \\
\hline I & Casacco - Piazza Noacco, Italija & 004561 & 35 & 0,0124 & 0,0088 & 0,705 \\
\hline ॥ & Gemona - Scugelars, Italija & 004558 & 35 & 0,0405 & 0,0177 & 0,438 \\
\hline III & Gemona - Li Furmie, Italija & 004559 & 38 & 0,0297 & 0,0129 & 0,436 \\
\hline IV & $\begin{array}{l}\text { Fakulteta za gradbeništvo in geodezijo, } \\
\text { Ljubljana }\end{array}$ & 006235 & 64 & 0,0246 & 0,0078 & 0,320 \\
\hline V & Ilirska Bistrica & 006236 & 87 & 0,0042 & 0,0022 & 0,537 \\
\hline
\end{tabular}

Vir: internet 2 
primer $k_{n}=1$ (dve vrsti ležǐšc) in $k_{m}=0,5$ (masa na polovici višine), mora biti v tem primeru $H / B=2$ ali manj, drugače bi se izolirani objekt prevrnil. $\mathrm{V}$ tem primeru je dovoljena vitkost odvisna od dejanskega razmerja pospeškov v vertikalni in horizontalni smeri ter jo je mogoče izračunati le $\mathrm{z}$ dinamično analizo za določen akcelerogram z znanim časovnim potekom pospeškov v horizontalni in vertikalni smeri.

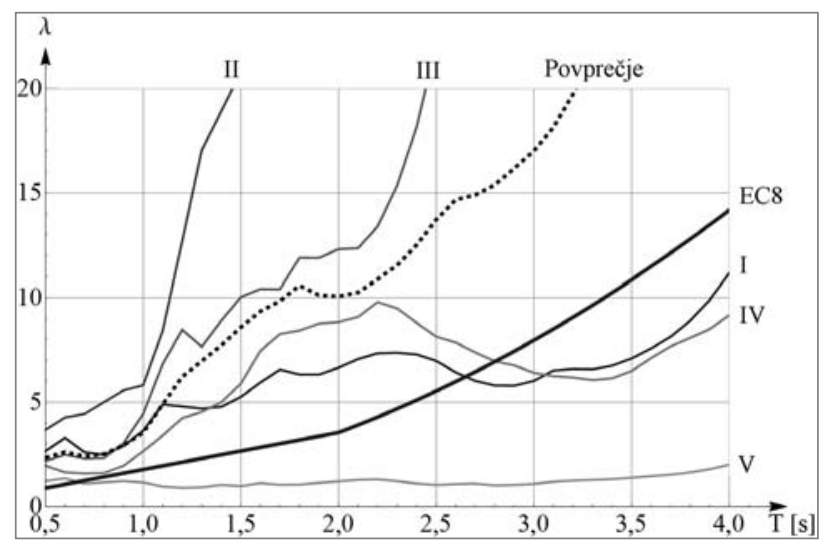

Slika 7: Maksimalne korigirane vitkosti objektov za izbrane akcelerograme potresa v Posočju leta 1998, dobljene z dinamično analizo.

\section{Sklep}

Ker lahko nepravilna in nepremišljena rekonstrukcija objekta povzroči večjo škodo kot kateri koli drug poseg, razen rušenja, morajo biti takšni posegi skrbno premišljeni. Še posebej zaželeno je, da je vpliv na arhitekturo objekta čim manjši. Kot določajo smernice za ohranjanje in upravljanje kulturne dedišcine, ki so naveden $\mathrm{v}$ listinah in mednarodnih resolucijah o varovanju spomenikov, lahko učinkovit izbor potresne izolacije dosežemo z izvajanjem interdisciplinarnih analiz tehnoloških, okoljskih in drugih vzrokov za poškodbe ter z izvajanjem dodatnih raziskav, ki lahko dopolnijo obstoječe načrte za prenovo.

Projektiranje ležǐšč potresne izolacije stavbe je dokaj zahtevno, saj gre za dinamičen sistem, $v$ katerem ima pomembno vlogo togost zgornje in spodnje konstrukcije. $\mathrm{V}$ članku so opisane splošne in nekatere posebne zahteve, ki jih je treba izpolniti pri projektiranju ležǐšc. Pri objektih z velikim razmerjem med višino in širino je namreč pomemben tudi pojav zibanja objekta (ang. rocking), ki ga povzročijo potresne sile in lahko pripelje do dviga ležišč oziroma prevrnitve potresno izoliranega objekta. $V$ teh primerih je mogoče določiti mejno vitkost objekta, ki bi ga še bilo mogoče postaviti na izolatorje, ne da bi zaradi delovanja horizontalne in vertikalne potresne sile prišlo do zibanja objekta oziroma do pojava nateznih napetosti $\mathrm{v}$ elastomernih ležiščih. $\mathrm{V}$ članku je prikazan izraz za račun maksimalnega korigiranega razmerja $H / B$, ki smo ga imenovali korigirana »vitkost «, pri čemer je dejansko razmerje (vitkost) korigirano $s$ faktorjema $k_{m}$ in $k_{n}$, ki zajemata vpliv lege masnega središča in vpliv števila vrst ležìšč.
Dovoljena razmerja so bila izračunana s pomočjo predpisa Evrokod 8 in s pomočjo dinamične analize za skalirane zapise potresa v Posočju leta 1998. Ugotovili smo, da je približen račun s spektrom v splošnem na varni strani. Posebno neugodne kombinacije vertikalnih in horizontalnih pospeškov pa lahko v določenih primerih pomenijo tudi povečanje nevarnosti prevrnitve objekta. Takšne okoliščine je mogoče predvideti le z dinamično analizo za določen akcelerogram z znanim časovnim potekom pospeškov v horizontalni in vertikalni smeri.

Sklenemo lahko, da je pogoj prevrnitve merodajen za izbiro ležišč, če je težiščce objekta visoko nad tlemi in je projektni pospešek tal velik. Pri nižjih objektih nastop nateznih napetosti v ležiščih ni merodajen pogoj za izbiro ležišč, na njihovo izbiro pa pomembneje vpliva še zahteva o omejitvi horizontalnega pomika in raven tlačnih napetosti $\mathrm{v}$ izolatorjih. $\mathrm{V}$ splošnem velja, da izolacija ni smiselna, če ne prinese tudi precejšnje redukcije sil v primerjavi z neizolirano konstrukcijo, saj bo morda drugače pri potresu še vedno prišlo do poškodb zgornje konstrukcije. Uporaba ležišč, ki dajo majhne redukcijske faktorje, s projektantskega stališča seveda ni smiselna niti ni cenovno upravičena.

Simon Petrovčič, univ. dipl. inž. grad., asistent

Univerza v Ljubljani, Fakulteta za arhitekturo, Ljubljana, Slovenija

E-pošta: simon.petrovcic@fa.uni-lj.si

David Koren, univ. dipl. inž. grad., asistent

Univerza v Ljubljani, Fakulteta za arhitekturo, Ljubljana, Slovenija

E-pošta: david.koren@fa.uni-lj.si

Dr. Vojko Kilar, univ. dipl. inž. grad., izredni profesor

Univerza v Ljubljani, Fakulteta za arhitekturo, Ljubljana, Slovenija

E-pošta:vojko.kilar@fa.uni-lj.si

\section{Viri in literatura}

Amerighi, L., Gatti, V., Indirli, M., Carpani, B., Martelli, A., Spadoni, B., in Alberti, A. (2007): The Montorio medieval tower: an architectonic study for a rehabilitation after the damage due to the 14th September 2003 earthquake. Elektronska publikacija. Istanbul, Anti-Seismic Systems International Society.

CEN (2004): Eurocode 8: Design of structures for earthquake resistance - Part 1: General rules, seismic actions and rules for buildings, EN 1998-1. Brussels, European Committee for Standardization.

Christopoulos, C., in Filiatrault, A. (2006): Principles of passive supplemental damping and seismic isolation. Pavia, IUSS Press.

Contento, A., in Di Egidio, A. (2008): Investigations into the benefits of base isolation for non-symmetric rigid blocks. Earthquake Engineering and Structural Dynamics, 38(7), str. 849-866.

Hino, J., Yoshitomi, S., Tsuji, M., Takewaki, I. (2008): Bound of aspect ratio of base-isolated buildings considering nonlinear tensile behavior of rubber bearings. Structural Engineering and Mechanics, 30, str. 351-368. 
ICOMOS (1993): Guidelines for education and training in the conservation of monuments, ensembles and sites. Dostopno na: http:// www.icomos.org/docs/guidelines_for_education.html (sneto 9. 2. 2009).

ICOMOS (1999): Burra Charter. Dostopno na: http://www.icomos. org/australia/burra.html (sneto 9. 2. 2009).

Indirli, M., Cami, R., Carpani, B., Algeri, C., Panzeri, P., Rossi, G. idr. (2006): The antiseismic rehabilitation of Marchesale Castle at San Giuliano di Puglia. Dostopno na: http://www.c-spin.eu/pubs/s.giuliano. pdf (sneto 19. 2. 2009)

Fajfar, P. (1984): Dinamika gradbenih konstrukcij. Ljubljana, Univerza v Ljubljani, Fakulteta za gradbeništvo in geodezijo.

Fister, P. (1979): Obnova in varstvo arhitekturne dediščine. Ljubljana, Univerza v Ljubljani, Fakulteta za arhitekturo.

Internet 1: http://www.takenaka.co.jp/takenaka_e/rodin_e/index. html (sneto 24. 2. 2009).

Internet 2: http://www.isesd.cv.ic.ac.uk/ (sneto 6. 4. 2009).

$\mathrm{Li}, \mathrm{H}$., in Wu, X. (2006): Limitations of the height-to-width ratio for base-isolated buildings under earthquake. The structural design of tall and special buildings, 15, str. 277-287.

Kelly, J. M. (1997): Earthquake-resistant design with rubber. Cambridge, Cambridge University Press.

Kilar, V., in Koren, D. (2007): Potresna izolacija stavb kot alternativa za gradnjo na potresnih območjih. Gradbeni vestnik, 56(12), str. 307-318.

Komodromos, P. (2000): Seismic isolation for earthquake resistant structures. London, WIT Press.

Koumousis, V. (2007): Design of the seismic isolation system for the statue of Hermes at the New museum of Olympia (paper \& presentation). Elektronska publikacija. Istanbul, Anti-Seismic Systems International Society.

Martelli, A., Forni, M. (1998): Seismic isolation of civil buildings in Europe. Progress in structural engineering and materials, 1(3), str. 286-294.

Martelli, A., in Forni, M. (2004): Development and application of modern antiseismic techniques in Italy. Dostopno na: http://www. assisi-antiseismicsystems.org/ (sneto 12. 2. 2009).

Naeim, F., in Kelly, J. M. (1999): Design of seismic isolated structures: From theory to practice. New York, John Wiley \& Sons, Inc.

Skinner, R. I., Robinson, W. H., in McVerry, G. H. (1993): An introduction to seismic isolation. West Sussex, John Wiley \& Sons Ltd.

Tomaževič, M., Klemenc, I., in Lutman, M. (1999): Posledice potresa na kamnitih zidanih hišah: Kaj smo se naučili od potresa, Ujma, 13, str. 122-128.

Zupančič, M. (2007): Vloga statične sanacije pri obnovi objektov arhitekturne dediščine. Varstvo spomenikov, 42-43, str. 228-236.

Zupančič, M., Kavčič, M., in Deanovič, B. (2007): Enotna metodologija za izdelavo konservatorskega načrta. Ljubljana, Zavod za varstvo kulturne dediščine Slovenije, Restavratorski center. 